This is an Accepted Manuscript of a book chapter published by Taylor \& Francis: Myers, T. and Allman, D. (1996). Bisexuality and HIV/AIDS in Canada. In P. Aggleton (Ed.), Bisexualities and AIDS: International Perspectives (pp. 22-42). London: Taylor \& Francis, available online: https://doi.org/10.4324/9780203421789 and https://www.taylorfrancis.com/books/9780203421789/chapters/10.4324/9780203421789-8

\title{
Bisexuality and HIV/AIDS in Canada
}

Ted Myers and Dan Allman

This chapter explores what is known about bisexuality and HIV/AIDS in Canada. It will focus primarily on research definitions, behavioural manifestations, and the political movement and organization of bisexuals in relation to HIV/AIDS. Published research, largely epidemiological, relating to the sexual behaviour of various populations since the beginning of the AIDS epidemic will be the predominant source of information. This documentation is critical because it is the only Canadian information currently available on bisexuality. While these data shed some light on the national picture as well as on regional variation, they ultimately raise more questions than answers. Scholarly reflection on sexuality in Canada and the placement of bisexuality along the continuum of human sexual relations is a discourse in its infancy. Our consideration of bisexuality in the arena of HIV/AIDS has had to take this into account.

We will first provide an overview of the sources of information on male bisexualities found in Canadian HIV/AIDS research. This will be followed by an examination of what is known from these sources regarding the proportion, distribution, social and ethnocultural characteristics, risk behaviour and the incidence of HIV infection among bisexual men. To illuminate the organization, social environment and societal responses to bisexuality, specific examples will be presented. Though many of the issues that influence the experiences of bisexuals can apply to both men and women, indeed, many of the issues may be the same, this chapter will focus exclusively on the bisexualities of men.

In terms of the number of detected infections and mortality in Canada, the HIV/AIDS epidemic has especially impacted on gay and bisexual men. Our focus on bisexual men by no means negates the experiences or realities of bisexual women, but rather reflects the patterns of HIV infection that we have witnessed in this country, and the implications this has for public health. As of October 1994, Health Canada reports 10,391 AIDS cases, 93.5 per cent of which are adult males. For 86 per cent of these, there is known sexual contact with a male. Eighty-nine per cent of Canada's AIDS cases have occurred in three of Canada's provinces, with 41 per cent in the Province of Ontario, 30 per cent in Québec and 18 per cent in British Columbia (Laboratory Centre for Disease Control, 1994). 


\section{Bisexuality and HIV Research in Canada}

In general, the study of sexuality in Canada remained relatively ignored until the HIV/AIDS epidemic. As in other developed countries, only in the last decade, with the realization that sexual behaviour was a primary means of transmission, has the realm of sex research begun to capture the attention of researchers and funding bodies. Unfortunately we cannot say that our review of the literature has been exhaustive. Until recently, there has been little interest in bisexual men. Few researchers have reported their results, and/or differentiated between gay and bisexual men. If a disproportionate amount of work by Myers and colleagues is reported in this paper, it is because it represents the bulk of published socio- behavioural research on gay and bisexual men and HIV in Canada.

Canadian data on bisexual men and HIV come primarily from targeted studies of men who have sex with men. Table 2.1 summarizes most of the Canadian research in which some attempt has been made to measure or define the proportion of the study population that is bisexual. This research may be roughly categorized into three types: general population surveys, studies of gay and bisexual men, and studies of other populations considered to be at risk for HIV infection, such as injecting drug users, prisoners and street youth.

In Canadian studies related to HIV, the proportion of bisexual men differs depending on the definition, method of study and study population. Ornstein's (1989) random telephone survey of AIDS in Canada found that the proportion of male adults in the general population who reported sexual activity (previous five years) with both male and female partners was 0.9 per cent. In The Canada Youth and AIDS Study, 1 per cent of male college and university students and 1 per cent of male high school dropouts reported that they were bisexual (King et al., 1991). A companion study found that 4 per cent of male street youth reported a bisexual orientation (Radford et al., 1991).

A report on a cohort of 249 men who had sex with an HIV infected male showed that 32 per cent had sexual activity with both men and women in the eight-year period prior to data collection (between 1978 when the virus was probably present in the population and the date of recruitment in 1985) (Coates et al., 1988; Calzavara et al., 1991). Men's Survey '90 (The Toronto Men's Survey) and the Canadian Survey of Gay and Bisexual Men and HIV Infection (The National Men's Survey) recruited men through gay-identified bars, bathhouses and, in the case of the latter, community dances. These studies found that 48 per cent of men and 54 per cent of men respectively reported sexual activity with both a man and a women in their lifetime (Myers et al., 1991; Myers et al., 1993a).

Interestingly, these studies of men who have sex with men have found that the proportion of the study population that report current bisexuality is fairly consistent, at about 13 per cent 
(definition based on reported sexual activity with both a man and a woman in the last year). Lower proportions were found in the larger metropolitan areas of Vancouver and Toronto than in smaller communities, with the exception of Montréal, where a higher proportion was found. A parallel study, Entre Hommes, conducted in the province of Québec found that overall, 11 per cent of the study population reported current bisexuality (Godin et al., 1993).

Canadian studies of men who have sex with men that have measured bisexuality have been primarily centred in the provinces of Ontario and Québec. These two provinces represent 65 per cent of the Canadian population. The National Men's Survey attempted an across-country comparison. Because of the varying sizes of Canada's gay communities, sampling by province was not possible. Consequently, it was necessary to stratify on a regional or metropolitan area basis. The data from The National Men's Survey show considerable regional variation in the lifetime sexual experience of the study population. Reports of sexual activity with both men and women ranged from a low of 35.2 per cent in the province of Québec to a high of 58.8 per cent in smaller communities in British Columbia, the Prairies, and Ontario.

Two studies of injecting drug users (IDUs), one an arm of the World Health Organization's Multicentre Study of Drug Injecting and HIV Infection, indicated that approximately 6 per cent of each of 500 and 809 male IDUs reported a current bisexual orientation (Millson et al., 1995a, 1995b). In addition, Hankins et al. (1994a) reported that 17 per cent of 1,408 IDUs indicated sexual activity with both a man and a woman in the last seven days.

Finally, 13 per cent of 971 male inmates in three medium security correctional institutions in Québec reported sexual activity with both a man and a woman in their lifetime, while 2 per cent reported themselves to be currently bisexual (defined as sexual activity with both a man and a woman in the six months prior to incarceration) (Hankins et al., 1994b).

\section{What Is Known about Bisexuality from Canadian Research}

There are no published reports in Canada in which any extensive attempt has been made to describe the characteristics of bisexual men and to distinguish these from homosexual or heterosexual men. To address this gap in part, an additional analysis of data from The Toronto Men's Survey was performed. Comparisons were made of three groups of men who have sex with men: those who reported sex with both men and women in the last year (currently bisexual), those who reported previous heterosexual experiences yet currently only had sex with men (gay-previous heterosexual) and those who, within their lifetime, indicated that they only had sex with men (gay lifetime).

Current bisexuals were younger than men identified as gay or gay but with previous heterosexual experience. Twenty-two per cent of the current bisexual group reported that they were less than 
25 years of age compared with approximately 9 per cent in the other two groups. At the same time, the current bisexual group was less likely to be in a steady relationship with a man (24 per cent) compared to 34 per cent of the gay men group and 44 per cent of the gay group with previous heterosexual experience. It was hypothesized that there would be ethnoracial differences between these three groups of men who had sex with men. In fact no significant difference was found. This may reflect a bias created by a recruitment that focused on bars and bathhouses within the organized gay community, as well as a research method that relied on a fairly high degree of English literacy. The venues in which these three groups of men socialize and seek sexual partners also vary. In general, a greater proportion of bisexual men were recruited through bathhouses than through gay bars or community dances. The Toronto Men's Survey showed that 65 per cent of the currently bisexual group were recruited through bathhouses compared to less than 50 per cent for each of the other two groups.

Though these data begin to provide some basic understanding of Canadian bisexual men, they are not comprehensive and may not necessarily reflect the current situation. For example, in the last several years there has been a major development in the commercial bar scene in the City of Toronto with the emergence of a number of alternative venues and clubs which serve ethnocultural groups of men, specifically latinos. We suggest that in Canada bisexuality may be more common in men from this population. Certainly this has been the finding in much of the Latin American literature (Lumsden, 1991).

\section{Sexual Behaviour and Risk}

While for the most part the risk behaviours of Canadian bisexual men have not been examined, The Toronto Men's Survey did include questions on eleven sexual activities that men may have engaged in during the past three months. When receded into a four-category variable reflecting level of risk (i.e. no sex, no anal intercourse, protected anal intercourse and unprotected anal intercourse), significant differences were found between the three subgroups of men, as shown in Table 2.2.

\section{Location and Residence of Bisexuals}

Extracted from The National Men's Survey, Table 2.3 shows these same three groups described above distributed across the seven sampling regions by which the country was stratified for the purpose of analysis: British Columbia and the Prairies excluding metropolitan Vancouver (VCR), Vancouver (BCP), metropolitan Toronto (TOR), Ontario excluding Toronto (ONT), metropolitan Montréal (MTL), Québec excluding metropolitan Montréal (QUE), and the Atlantic Region (ATL). Two of the sampling strata were predominantly francophone (MTL and QUE). The remaining strata were anglophone. The large sample size $(4,803)$ ensures that the variation in proportions is meaningful. 
The lowest proportion of bisexual men was found within the two English-speaking, metropolitan strata of Vancouver and Toronto. This trend was reversed in the province of Québec, including metropolitan Montréal. It has been suggested that unique differences between French and English Canada in terms of patterns of socializing, language, socialization to sexuality, and religion may account for the differences in these proportions of bisexual men. Certainly, patterns of socializing in the francophone and anglophone gay communities differ. For example, the city of Montréal has many more bathhouses than other cities in the country.

\section{AIDS Hotline-An Exploratory Study}

The scarcity of information on bisexual men in Canada is such that in order to develop a protocol for a future study, the authors, with the assistance of the Ontario Provincial AIDS hotline, conducted a brief feasibility study in the spring of 1994 to assess the application of the telephone as a device to recruit and interview men who have sex with both men and women. During a twoweek period, callers to the hotline who volunteered that they had sex with both men and women were asked if they would agree to answer a number of questions. Almost all agreed. Sixty-one per cent of the bisexual callers were from outside of the metropolitan Toronto area.

\section{Relationship Status and Disclosure of Bisexuality}

Forty-four per cent of the men who called the hotline were in a primary relationship with a female with occasional contact with male partner(s), 22 per cent indicated that they were in frequent contact with a variety of male and female partners, and 11 per cent indicated either that they were in a primary relationship with a male but had occasional sexual contact with females, or that they were in a dual relationship with both a man and a woman. Approximately one-third of the men who called the hotline reported that they had disclosed their bisexuality to both male and female partners, one-third of the men disclosed their bisexuality to male partners only, and 20 per cent disclosed to female partners only.

\section{Ways of Meeting Sexual Partners}

Few of the callers to the hotline indicated that they met their sexual partners in bars or bathhouses. Rather, 41 per cent indicated that introductions by way of their social networks (not necessarily bisexual networks) were the predominant form of meeting male sexual partners, followed by encounters with partners through parks, washrooms, and automobile parking areas ( 24 per cent). An additional 24 per cent indicated they met their male sexual contacts through classified advertisements. 


\section{Personal Classified Advertisements-An Exploratory Study}

Allman (1994) content-analysed a systematic sample (1 in 10) of three years of voice and personal classified advertisements placed in prominent Canadian gay media. Advertisements $(\mathrm{N}=649)$ were coded for the advertiser's sexual orientation, socio-demographic characteristics, the type of relationship or exchange desired, and the risk level of the requested activity as defined in the Canadian AIDS Society's Safer Sex Guidelines (1994). Frequently much of this information was not manifest within the text of the advertisement. Only 'codeable' advertisements that specified relevant information were included in this analysis.

Generally self-identified bisexual men were younger. Twenty-four per cent of bisexual men were below the age of 25 compared to 10 per cent of gay-identified men, while only 15 per cent of bisexual men were over the age of 40 compared to 30 per cent of gay men. There was little variation in ethnicity. Over 80 per cent of both bisexual and gay-identified men were Caucasian. Sixty per cent of advertisements placed by gay-identified men requested a permanent, monogamous or long-term relationship compared to 16 per cent of those placed by bisexually identified men; while 84 per cent of advertisements placed by bisexual men requested casual sexual activity compared to 40 per cent of the advertisements placed by gay men.

In terms of risk, there was a trend for self-identified bisexual men to specify or request riskier sexual activities such as insertive and receptive anal sex. Seventy-four per cent of bisexual men specified sexual activity with some element of risk compared to 60 per cent of gayidentified men. This reflects a different pattern of risk from that found in Canadian venue-based studies, which may be because the two mediums - print and telephone - attract men of different sexual orientations or identifications. Only 7 per cent of print advertisements were placed by men who were bisexually identified, though this same group placed over 70 per cent of the voice advertisements.

\section{HIV Antibody Testing and HIV Infection among Bisexuals}

Canadian data on HIV antibody testing among bisexual men are limited. In 1990, The Toronto Men's Survey showed bisexual men were less likely to have been tested for HIV antibodies than gay men or than gay men with previous heterosexual experience ( 42 per cent compared to 56 per cent in the other two groups). However, in 1991, The National Men's Survey demonstrated that an almost equal proportion of bisexual men had been tested for HIV as had gay men (60 per cent). The survey also showed the self-reported rate of HIV infection among the currently bisexual group ( 7 per cent) was slightly more than half that reported by the gay men or the gay men with previous heterosexual experience (12 per cent). 
In addition to the studies described above, data have been made available from HIV antibody testing programmes. In the province of Ontario there are three formats for HIV antibody testing: anonymous, non-nominal and nominal. For the period January 1992 to June 1993, 10 per cent of men who tested anonymously were defined on the basis of sexual activity as bisexual compared with 1 per cent of men tested non-nominally and 0.4 per cent of men who tested nominally (Ontario Ministry of Health, 1994).

True estimates of the incidence of the HIV antibody in the Canadian population are not available. In fact the best estimates of Canadian HIV seroprevalence are derived from studies that focus on specific subgroups such as pregnant women, street youth and IDUs. Bisexuals have not been the target of such studies. In addition, there are only a limited number of studies that report on the seroprevalence of gay and bisexual men, and they do so without making the distinction between those men who are gay and those who are bisexual (Schechter et al., 1987; Coates et al., 1988). The scarcity of seroprevalence studies of gay and bisexual men is indicative of their controversial nature. In Canada, two reasons in particular have been used by community groups and AIDS activists to oppose seroprevalence studies. One is disagreement about the effects of such studies on the population, and the other concerns the generalizability of the results as it is not possible to determine the size of the base population on which to calculate prevalence rates.

In the Ontario voluntary HIV antibody testing programme, the seroprevalence rate among men who have sex with both men and women is lower for men testing in the anonymous programme (3.2 per cent) compared to men testing non-nominally or nominally ( 4.8 per cent and 5.2 per cent respectively). This is generally lower than for those men who had sex with men only with rates in the same testing modes being 6.0 per cent, 7.9 per cent and 5.6 per cent respectively (Ontario Ministry of Health, 1994).

The Ontario Ministry of Health Laboratory reports that between August and October 1993, 10 per cent of all known seroconversions involved bisexual men. Among bisexuals who were tested, 3.5 per cent were HIV antibody positive compared to 7.4 per cent of men who only reported sex with men. At the same time, 40 per cent of all positive tests of the bisexual group were seroconversions compared to only 17 per cent of the other groups. The British Columbia Centre for Disease Control report on seropositivity among street-involved persons in Vancouver (1988-92) reflects an overall rate of infection among bisexuals of 7.2 per cent compared to 16.1 per cent among homosexual men (Rekart, 1993).

Overall, Canadian research has failed to capture detail on the bisexual male and HIV/AIDS, even though information may be paramount in terms of understanding transmission of the virus. In spite of the fact that transmission of HIV from bisexual men to women is a primary concern, no attempts have been made to explore the extent to which this is happening. 
While the authors sense an increasing interest in bisexuality on the part of the Canadian HIV research community, this is not reflected chronologically in the research (see Table 2.1). Despite the flaws that the research reported in this chapter present, the data do provide a baseline for future research.

\section{The Conceptualization of Bisexuality in Canadian Research}

The conceptualization of bisexuality in the fourteen Canadian studies described in this paper varies little. Essentially, two definitions have been used, one based on behaviour and the other on self-reported identity. The behavioural definitions fall primarily into two temporal dimensionslifetime sexual experience with women and men, and sexual behaviour in the last year.

An analysis of data from The National Men's Survey comparing respondents on the basis of their behaviourally defined sexual orientation and their self-reported sexual identity reflects moderate agreement between the two definitions with 62 per cent of those whose current behaviour was bisexual (sex with men and with women in the last year) self-identifying as bisexual. An additional 31 per cent identified as gay, and 3 per cent as heterosexual. For those classified as behaviourally gay (sex with men only), and gay with previous heterosexual experience, agreement with sexual identity was greater, with 98 per cent and 88 per cent respectively indicating that they were gay or homosexual.

That behavioural definitions have been dominant in AIDS research reflects the emphasis on risk found in epidemiological thought. HIV risk has seldom been measured along a continuum. The way bisexual behaviour has been described provides us with a very limited understanding of bisexuality. It does not permit distinctions to be made between groups or individuals, and may not reflect how Canadian bisexuals perceive their own sexuality.

\section{Sexual Communities}

In modern societies we have come to define communities beyond geographical or political boundaries and view them as communities formed around common purposes, experiences, goals and objectives. To understand the variation in the proportions of bisexuals represented in the above studies and the forms of bisexuality requires some understanding of the organization of sexuality in Canadian society. Prior to describing Canada's social and public health response towards the bisexual in relation to HIV/AIDS, we will briefly reflect on some of the interaction between the gay and bisexual communities, as well as some of the reactions of the larger society. Whether or not a bisexual community exists may be the basis for debate. There is recent reference by organized bisexuals to a Canadian 'bisexual community' although this is generally seen as a future scenario (OBN News, July/August 1993). 


\section{Bisexual Networks, Organizations and Communities}

It is unclear what proportion of the country's bisexuals operate within or identify with organizations such as the Ontario Bisexual Network (OBN). Many bisexual men and much of their sexual activity remain hidden. In some communities anecdotal accounts surface of individuals who provide an opportunity for bisexuals to connect or to be introduced. Theoretically these meetings are generally organized on a very informal basis. It is a phenomenon that is not well understood, and not at all researched. According to Graydon (1994)

these men: create a network of contacts and informal sex clubs where men meet. Some informal sex clubs may be managed by one person, a kind of gate keeper, who possesses a method for contacting all players, while individual players are able only to contact him. The gate keeper arranges and hosts evenings for sex, matching up various individuals. Informal clubs may exist for weeks, perhaps while a spouse is away, or evolve to continue for years. It is not unusual that gate keepers are gay men who have made contacts with [bisexual men] over the years and who possess a place to host events.

In larger cities such networks may become more structured and organized with newsletters containing editorials, letters, articles, information and other opportunities for exchange. For example, the OBN describes itself as:

a group formed to enable contact among bisexual people in Ontario, and to help them undertake activities of interest. At present, these activities include: a mailing list, a newsletter, support group meetings, social activities, a political action group, education of others, information sharing, and safe sexuality information. The network's only mandate is to bring people together. (OBN Meeting, 2 August 1990 as referenced in OBN News, May 1991)

The uniqueness of this type of organization distinguishes it from gay and lesbian groups. The OBN claims to have no overall philosophy, culture, set of beliefs or any characteristics to which one must conform, nor is the organization formed around any political agenda. Further, these groups hold a clear opposition to consensus decision-making, believing that such a model is outdated and oppressive (OBN News, July/August 1993). A possible movement towards organization and community development is reflected through some of the questions raised by the OBN. For example:

- Should anyone create a 'Bisexual Movement'?

- Could the idea of a movement in itself confine the bisexual action in time?

- Is anything restricted from the movement doomed to inertia, stagnation?

- How can this movement be liberating and for whom? 
Questions such as these were part of the agenda for discussion at the first annual general meeting of bisexual community groups in Ontario, held in 1993.

\section{Gay and Lesbian Communities: Structure and Politics}

Compared to Canadian bisexual communities, the organization and structure of the gay and lesbian community is much more expansive. The evolution of organized gay communities, and their political philosophies, have had an impact on bisexual community development. Among the critiques made by some gay activists in response to the increased visibility of bisexuals are the ideas that bisexuals are 'fence sitters', unable to choose between homosexuality and heterosexuality, or that bisexuals are 'confused', and their activity with both men and women is simply part of the difficult process of coming out. Some have even insinuated that bisexuals are 'piggy-backing' on gay and lesbian activism; that they wish to appropriate all the political and social advances attained by the gay movement, while maintaining the inherent freedoms and privileges of a heterosexist and homophobic society.

Overall, the political agenda of lesbian and gay communities has been more clearly defined and open, influenced in part by the strong identification that these communities have fostered. Perhaps it is because of the difficulties that many gay and lesbian organizations have had in establishing and securing gay-positive communities, as well as the need to maintain a distinction between 'straight' and 'queer' politics, that bisexuals have been excluded from the membership. For example, in one major metropolitan area, a community-funded counselling centre for lesbians and gay men preserves a policy that permits bisexuals to receive service but not to provide the same or to be a board member of the organization. Even though some of Canada's boldest opponents of racism, classism and ableism have been lesbian and gay communities, the policies, actions and opinions of some of these same communities in response to bisexuals can be labelled nothing less than biphobic.

Slowly, however, long-standing Canadian gay and lesbian organizations are beginning to change their stance, and we are currently witnessing a greater acceptance of bisexuality. This is evident in the actions of some community organizations, who have recently altered their names to include the term 'bisexual', though whether this reflects an actual change in the politics and mission statements of these groups, or is simply a semantic alteration for public relations, has yet to be determined. 


\section{HIV Education and Bisexualities}

In the early stages of the HIV epidemic the primary concern of public health officials was prevention. Until this point Canadian public health prevention and disease control initiatives had generally relied upon legislation and traditional control methods such as contact tracing. The arrival of AIDS coincided with a trend towards a 'new public health', one which embraced the principles of health promotion. Such a model favoured the provision of information and resources to individuals in order to enable and empower them to achieve and maintain their own health. Combined with this new public health paradigm was the realization that traditional models of prevention and response were not feasible or practical. In many cases an individual's contacts or sex partners would be anonymous and/ or multiple. The case of bisexual men further confounded the process. Here there was the added issue of informing wives who may not have known of their husbands' activities.

Since the inception of the epidemic and the identification of unprotected anal and vaginal intercourse as major routes of HIV transmission, there has been an awareness of the risks to which Canadian bisexual men may be putting themselves and others. In addition to those they face in terms of their own health, their behaviour may entail even more risk due to their sexual activities with both men and women. From the beginning, transmission from bisexual men to their potentially unsuspecting female partners has been a concern. Some of the early incidents of HIV infection in Canadian women were cases where sexual activity with a male bisexual was identified as a risk factor. Yet, in spite of this, much of the preventive educational material aimed at transmission has referred to gay and bisexual men as a homogenous group. Early interventions applicable to bisexual men were really focused on homosexuals. This response was typical of both public health officials and community-based AIDS service organizations. HIV prevention campaigns generally avoided explicit mention of bisexual behaviour or the sexual activity of one individual with partners of both sexes. Instead efforts developed by AIDS service organizations emphasized peer group support and community building. Further, any images or messages that made reference to bisexuality did so within the context of gay identity.

In Ontario, the first educational print materials dealing with transmission facts were produced in 1983 and though the fine print did refer to bisexual men, the predominant slogan, catch phrase and sound bite was 'Gay Sex and AIDS'. By 1985, safer sex campaigns became more focused on specific messages dealing with oral and anal sex, with additional targeting to groups such as men involved in sadomasochism, and the hearing-impaired. Male bisexuals were not targeted until 1987.

Educational initiatives aimed at bisexuals have not been extensively distributed throughout the country. For the most part, public health agencies have chosen not to deal specifically with bisexual or even homosexual issues, and are often accused of being generally 
homophobic for their way of tackling these issues. In Toronto, the Department of Public Health became the first Canadian agency of its kind to develop an AIDS Operational Plan. The plan acknowledged bisexuality and aimed 'to provide support for risk reduction programmes for specific target groups such as drug users, prostitutes, homosexual and bisexual men and individuals with multiple sex partners' (City of Toronto, 1987).

\section{A Media Intervention for Bisexuals: A Case Example}

Though public health response has been generally tentative, one daring educational initiative was created by the Ontario Ministry of Health. In 1990 the Ministry, on the advice of the Ministry's advisory committee recognizing the need for an educational campaign directed at bisexual men, developed a television campaign directed at five sub-populations: gay men, young women, families, IDUs and bisexual men. The process involved in the creation of the bisexual commercial included four objectives: (1) to make bisexual men aware of the risk of contracting AIDS; (2) to encourage responsible behaviour towards both male and female partners in order to protect them from HIV infection; (3) to encourage bisexual men to talk to their partners, especially female partners; and (4) to make female partners of bisexual men aware that they themselves were at risk. Certainly this was not an easy venture. Difficulties were first encountered because of the lack of research. There were no data on this group and no clear understanding about what messages might best motivate behaviour change. Second, it was conceptually difficult to know how best to typify the bisexual man and then to locate representative individuals to participate in focus groups. Ultimately the process involved the recruitment of two groups of men who currently were having sex with men, one made up of gay fathers who recently had been involved in marriages and who had children, and another comprised of men still in relationships with women.

The main goal of these focus groups was to find out what would motivate bisexual men to change their behaviour. According to participants, the answer was neither disclosure of samesex activity to the spouse, nor the idea of self-protection. Rather, the strongest motivational factor was concern for one's family. This insight formed the basis of the first paid television advertisement of its kind in Canada. It portrayed a bisexual man returning home after a sexual encounter with a man, and expressing anxiety for not having used a condom, and concern over what this might mean for his spouse and family.

Night. Inside a car. Male driver, 30, looks into the car mirror.

We didn't use a condom... He didn't want to...

I should know better. What if I get AIDS?

I could give it to Marie...wreck my family. 
Announcer: If you have unprotected sex — even once-with a man...or a woman, you're risking everything. Cut the risk. Use a condom. Take charge...take care.

(Ontario Ministry of Health, 1992)

Though government officials and consultants developed the advertisements, approval by politicians was required. All five of the targeted population advertisements were tested for public reaction prior to wide media release, but the bisexual one also was subjected to an additional round of testing. Feedback from phone interviews in a field test of the advertisement found that 92 per cent of those who had seen the advertisement could recall some of its content, and approximately 75 per cent were left with a positive impression. Only 12 per cent of the people surveyed reacted negatively. Some people were opposed to a message that appeared to condone 'infidelity', but the evaluation concluded that the general public recognized a need for the advertisement. First shown in 1992, it continues to air today. Meanwhile the Ministry of Health is providing resources to a variety of ethnocultural groups to develop targeted campaigns. In consultation with their communities, the Chinese, Portuguese, Polish, South Asian, Caribbean and Spanish have chosen to focus at least part of their television campaigns on bisexual men.

\section{The Barriers, Challenges and Priorities for Research on Bisexualities in Canada}

As indicated earlier in this chapter, HIV/AIDS has elevated human sexuality issues within the Canadian research community by increasing the number of persons interested in conducting research into human sexuality, and by making national and provincial funds available for such research. This chapter illustrates the limited extent to which initiatives have dealt with bisexuality. While research efforts have focused on some vital populations, for the most part the field has been dominated by biomedical and epidemiological research models, methods and criteria (National AIDS Secretariat, 1994).

HIV/AIDS in many ways has reshaped the way research is carried out. Firstly, we have seen a blending of many of the traditional disciplines. Among epidemiologists there is increased recognition of the importance of behaviour in order to understand where the epidemic is going (Chin, 1994). Boulton (1994) has emphasized some of the challenges in this area. She has noted that many of the behaviours thought to transmit HIV are private and difficult to investigate, and many of the people considered to be at high risk of HIV infection are among the least accessible to social research.

Evidence of the evolution - and need for further reshaping of the way research is carried out in Canada - is reflected in a working document prepared for Phase II of Canada's National AIDS Strategy. In the statement of principles developed for this discussion document, the importance of consultation and collaboration between researchers and community is emphasized (National AIDS Secretariat, 1994). While the principle of community-based involvement may be 
important to the study of bisexualities, there are logistical barriers to such an approach due to the lack of organization and the hidden nature of the population (Myers and Allman, 1995). Unlike many other marginalized minority and cultural groups, bisexuals are more likely to be scattered and not geographically grouped or centred. The potential for the development and mobilization of a bisexual community would seem to be low — particularly for the heterosexually identified man who has sex with men.

While in general it would appear easier to undertake research in Canada on male bisexual communities and bisexual activity than it would be in other, less developed countries, this is not necessarily the case. Preparatory and developmental work is required of Canadian society in general as one of the major barriers to research has been the country's response to bisexuality. Canadian society has marginalized bisexuals and has responded to them with even greater intolerance, suspicion and confusion than to other groups of men who have sex with men. This is seen in both the response by the lesbian and gay community and by society at large. The sophistication and community development of the gay and lesbian communities, and their stances on bisexuality, have meant that many of these men have chosen to remain hidden beneath heterosexual and homosexual identities. In the years since the emergence of AIDS, police have continued to arrest men, many of whom are bisexual, in public places such as washrooms where sex is known to occur (Globe and Mail, 5 July 1993; Globe and Mail, 3 September 1993). While HIV/AIDS educators have for some time seen the need for outreach in the locations where men meet and engage in sexual activity such as parks and washrooms, only now are we beginning to see attempts to contact these men in their milieu. Organizations who choose to initiate programmes discover that extensive effort is required. The issue is twofold. While educators wish to tread carefully so as not to scare away these men who have sex with men, they do wish to guarantee the safety and security of outreach personnel and volunteers.

Techniques to locate these men for educational and prevention purposes and to recruit these men for research may be similar. In some communities, the success of initiatives may not rest solely with the social organization of bisexual men but also with the police, public health officials and the judicial system. These authorities may have policies that scrutinize places where bisexual men may be seeking sexual partners, and therefore limit outreach and contact with these men. As suggested earlier by Allman's analysis (1994), some of the more traditional methods of contacting and finding sex partners may be replaced by the modern technologies of telephone networks and computer bulletin boards.

In the absence of a strong foundation of research into bisexualities and HIV/AIDS in Canada, the research agenda remains open. Following Chu et al. (1992) we can identify a number of critical issues for study in Canada. Risk behaviour, as discussed in this chapter, has been too closely defined in the context of gay sex. Often the assumption is that bisexual men do not take precautions and do not disclose their sexual activity to female partners. This has never 
been empirically confirmed. In addition greater understanding is needed of the social and sexual networks of bisexuals. Some preliminary qualitative work within ethnocultural groups has shown there are important differences to explore (Adrien et al., 1994). While researchers have found some difference in homosexual and bisexual activity between English and French language groups in Canada, we do not understand why this is so, or whether similar differences exist for other language groups.

\section{Canadian Sexuality and Bisexuality in Perspective}

Canada is one of the largest of the world's developed countries, with a land mass of almost 10 million square kilometres. In contrast the population is relatively small with only 27 million inhabitants. Canadian sexualities would appear to reflect an environment characterized by a vast and varied terrain, a mitigating climate and a population of fluctuating density. Historically this country's reputation as 'the new world' has implied a land of opportunity, and as a result Canada continues to attract new immigrants from every country in the world. Rather than promote a melting-pot society, our multicultural policies celebrate differences between communities. Though this culture has evolved side by side in a symbiotic relationship with the United States, we believe there remains a unique Canadian identity.

The racial heritages and ethnocultural backgrounds of the original settlers and the subsequent displacement of First Nation or aboriginal people have impacted on our perceptions of sexuality (Bullock, 1995). As well, the social and political organization of the ten provinces and two territories and Canada's role in international politics bear upon what is known and understood about sexuality and bisexuality in the country. Canada has been described as a 'Vertical mosaic' (Porter, 1969), a multitude of institutionally complete ethnic communities that permit wide variation in community association - and, we would add, sexual identification. That some men from these communities would engage in sexual activity with both men and women is not in question. What we do not know is how the sexual norms of each of these communities may interact within a Canadian context.

It is the authors' contention that bisexuality has long been ignored in Canada's HIV/AIDS prevention, education and research efforts. Ultimately, it has not been possible in this chapter to explore all of the themes that 'Canadian bisexualities' may suggest. Hard data on bisexuality have not been readily available and in deference, a wide variety of sources have been collected in order to uncover what, for the most part, has been an untouched subject. 


\section{References}

ALLMAN, D. (1994) 'Personal Classified Advertisements of Men Seeking Sex with Men: Trends in Representations of Risk Behaviour, 1980-1994', presentation at the Fourth Annual Canadian Conference on HIV/AIDS Research, Toronto, Ontario.

BOULTON, M. (1994) 'The Methodological Imagination', in BOULTON, M. (Ed.) Challenge and Innovation: Methodological Advances in Social Research on HIV/AIDS, London, Taylor \& Francis.

BULLOCK, S.L. (1995) 'The Perceptions of Sex among First Nations People Living OnReserve in Ontario', unpublished Masters thesis, University of Toronto.

CALZAVARA, L., COATES, R., JOHNSON, K., READ, S., FAREWELL, V., FANNING, M., SHEPHERD, F. and MACFADDEN, D. (1991) 'Sexual Behaviour Changes in a Cohort of Male Sexual Contacts of Men with HIV Disease: A Three Year Overview', Canadian Journal of Public Health, 82, 3, pp. 150-6.

CANADIAN AIDS SOCIETY (1994) Safer Sex Guidelines: Healthy Sexuality and HIV. A Resource Guide for Educators and Counsellors, Ottawa, Canadian AIDS Society.

CHIN, J. (1994) 'HIV/AIDS Surveillance: How Accurate and/or Useful Are the Numbers?', presentation at the Fourth Annual Canadian Conference on HIV/AIDS Research, Toronto, Ontario.

CHU, S.Y., PETERMAN, T.A., DOLL, L.S., BUEHLER, J.W. and CURRAN, J.W. (1992)

'AIDS in Bisexual Men in the United States: Epidemiology and Transmission to Women', American Journal of Public Health, 82, 2, pp. 220- 4.

CITY OF TORONTO, DEPARTMENT OF PUBLIC HEALTH (1987) AIDS Operational Plan Implementation Proposal 1987-1989, Toronto, Ontario.

COATES, R., CALZAVARA, L., READ, S., FANNING, M., SHEPHERD, F., KLEIN, M., JOHNSON, J. and SOSKOLNE, C. (1988) 'Risk Factors for HIV Infection in Male Sexual Contacts of Men with AIDS or an AIDS-Related Condition', American Journal of Epidemiology, 128, 4, pp. 729-39.

GLOBE AND MAIL (1993a) Toronto, Ontario, 5 July.

GLOBE AND MAIL (1993b) Toronto, Ontario, 3 September.

GODIN, G., CARSLEY, J., MORRISON, K. and BRADET, R. (1993) Entre hommes 91- 92: Les comportements sexuelles et l'environment social des hommes ayant des relations sexuelles avec d'autres hommes, Québec, COCQ sida.

GRAYDON, M. (1994) 'Divided Loyalties-Reaching Straight Men who Have Sex with Men: Safer Sex Outreach to Heterosexually Identified Men who Have Sex with Men', paper at 8th Annual British Columbia HIV/AIDS Conference, November.

HANKINS, C., GENDRON, S. and TRAN, T. (1994a) 'CACTUS-Montréal: Profile comportemental de la clientèle et prévalence de l'infection par le VIH', Rapport 5, December. 
HANKINS, C., GENDRON, S. and TRAN, T. (1994b) Risk Factors for HIV Infection in Inmates of Medium Security Correctional Institutions, Montréal, Centre for AIDS Studies.

KING, A., BEAZLEY, R.P., WARREN, W.K., HANKINS, C.A., ROBERTSON, A.S. and RADFORD, J.L. (1991) Canadian Youth and AIDS Study, Kingston, Social Program Evaluation Group, Queen's University.

LABORATORY CENTRE for DISEASE CONTROL, Division of HIV/AIDS Epidemiology, Bureau of Communicable Disease Epidemiology, Health Canada (1994) Surveillance Update: AIDS in Canada, Ottawa, October.

LUMSDEN, I. (1991) Homosexuality: Society and the State in Mexico, Toronto, Canadian Gay Archives.

MILLSON, P., MYERS, T., RANKIN, J., MCLAUGHLIN, B., MAJOR, C., MINDELL, W., COATES, R., RIGBY, J. and STRATHDEE, S. (1995a) 'Prevalence of Human Immunodeficiency Virus and Associated Risk Behaviour in Injection Users in Toronto', Canadian Journal of Public Health, 86, $3 / 4$.

MILLSON, P., MYERS, T., RANKIN, J., FEARON, M. and MAJOR, C. (1995b) 'WHO Multicentre Study of Drug Injecting and HIV Infection', Toronto Centre, Final Report of NHRDP Grant 6606-4694-AIDS.

MYERS, T. and ALLMAN, D. (1995) The HIV/AIDS Epidemic and Community- Research Partnerships in Canada', in READY, M. and TAGGART, M.E. (Eds) 'Une Approche heuristique et multidisciplinaire. Réflexions et stratégies pour les professionels de la santé', Montréal, Morin Ltée.

MYERS, T. and CLEMENT, C. (1994) 'Condom Use and Attitudes among Heterosexual College Students', Canadian Journal of Public Health, 85, 1, pp. 51-5.

MYERS, T., LOCKER, D., ORR, K. and JACKSON, E. (1991) Men's Survey '90-AIDS: Knowledge, Attitudes, Behaviours. A Study of Gay and Bisexual Men in Toronto, Toronto, AIDS Committee of Toronto.

MYERS, T., TUDIVER, F., KURTZ, R., JACKSON, E., ORR, K., ROWE, C. and BULLOCK, S. (1992) 'The Talking Sex Project: Description of the Study Population and Correlates of Unsafe Sexual Practices at Baseline', Canadian Journal of Public Health, 83, 1, pp. $47-52$.

MYERS, T., GODIN, G., CALZAVARA, L., LAMBERT, J. and LOCKER, D. (1993a) Canadian Survey of Gay and Bisexual Men and HIV Infection: Men's Survey, Ottawa, Canadian AIDS Society.

MYERS, T., CALZAVARA, L., COCKERILL, R. and MARSHALL, V. (1993b) Ontario First Nations AIDS and Health Lifestyle Survey, Toronto, University of Toronto.

NATIONAL AIDS SECRETARIAT (1994) Towards a National HIV/AIDS Research Planning Process: A Discussion Paper, Ottawa, National AIDS Secretariat.

OBN NEWS (1991) Toronto, Ontario, May.

OBN NEWS (1993) Toronto, Ontario, July/August. 
ONTARIO MINISTRY OF HEALTH (1992) HIV/AIDS Education in Ontario: From Information to Behaviour Change, the Evolution of AIDS Television Advertising, Toronto, Ontario Ministry of Health.

ONTARIO MINISTRY OF HEALTH (1994) Anonymous HIV Testing Evaluation- January 1992 to June 1993, Toronto, AIDS Bureau.

ORNSTEIN, M.D. (1989) AIDS in Canada, Toronto, University of Toronto Press.

PORTER, J. (1969) The Vertical Mosaic: An Analysis of Social Class and Power in Canada, Toronto, University of Toronto Press.

RADFORD, J., KING, A. and WARREN, W. (1991) Street Youth and AIDS, Kingston, Social Program Evaluation Group, Queen's University.

READ, S., DEMATTEO, D., BOCK, B., COATES, R., GOLDBERG, E., KING, S., MAJOR, C., MCLAUGHLIN, B., MILLSON, M. and O’SHAUGHNESSY, M. (1993) HIV Prevalence in Toronto Street Youths, Toronto, Hospital for Sick Children.

REKART, M. (1993) Trends in HIV Seroprevalence among Street-Involved Persons in Vancouver, Canada (1988-1992)', presentation at the IXth International Conference on AIDS, Berlin.

SCHECHTER, M.T., BOYKO, W.J., CRAIB, K.J.P., MCLEOD, A., WILLOUGHBY, B., DOUGLAS, B., CONSTANCE, P. and O'SHAUGHNESSY, M. (1987) 'Effects of Long-Term Seropositivity to Human Immunodeficiency Virus in a Cohort of Homosexual Men', AIDS, 1, pp. 77-82.

NB Tables available available online or in print: https://doi.org/10.4324/9780203421789 and https://www.taylorfrancis.com/books/9780203421789/chapters/10.4324/9780203421789-8 